\title{
Network planning evaluation implementing time varying thermal ratings
}

Link to publication record in Manchester Research Explorer

\section{Citation for published version (APA):}

Kapetanaki, A., Kopsidas, K., Tumelo-Chakonta, C., \& Buhari, M. (2014). Network planning evaluation implementing time varying thermal ratings. In Probabilistic Methods Applied to Power Systems (PMAPS): 2014 International Conference (pp. 1-6). IEEE.

\section{Published in:}

Probabilistic Methods Applied to Power Systems (PMAPS)

\section{Citing this paper}

Please note that where the full-text provided on Manchester Research Explorer is the Author Accepted Manuscript or Proof version this may differ from the final Published version. If citing, it is advised that you check and use the publisher's definitive version.

\section{General rights}

Copyright and moral rights for the publications made accessible in the Research Explorer are retained by the authors and/or other copyright owners and it is a condition of accessing publications that users recognise and abide by the legal requirements associated with these rights.

\section{Takedown policy}

If you believe that this document breaches copyright please refer to the University of Manchester's Takedown Procedures [http://man.ac.uk/04Y6Bo] or contact uml.scholarlycommunications@manchester.ac.uk providing relevant details, so we can investigate your claim.

\section{OPEN ACCESS}




\title{
Network Planning Evaluation Implementing Time Varying Thermal Ratings
}

\author{
Alexandra Kapetanaki, Konstantinos Kopsidas, C.Tumelo-Chakonta, Muhhamad Buhari \\ The University of Manchester, Manchester, United Kingdom \\ alexandra.kapetanaki@manchester.ac.uk \\ k.kopsidas@manchester.ac.uk
}

\begin{abstract}
Contemporary transmission networks are not fully utilized due to increased uncertainty and security buffers resulting mainly from the inefficient operation and planning, currently based on conservative predetermined thermal ratings. However, in a smart operation scheme, which considers time varying thermal ratings of transmission assets, operation and planning could be optimized to facilitate the proliferation of generation expansion projects while maintaining required levels of reliability. This paper presents a methodology which enhances the current methods of network element ratings by incorporating a more detailed modelling of the overhead line (OHL) properties. Three thermal rating models, static (STR), seasonal (SeTR) and time varying (TVTR), are implemented for comparative studies, under both deterministic and probabilistic frameworks with an aim to identify the most cost-effective and optimal flexible network operation plan in today's congestion-driven and competitive power markets. In addition, the effects of line outages on transmission losses in the electric power networks are presented, quantifying the transmission losses in a realistic manner due to the incorporation of real thermal ratings. The IEEE 24-bus RTS is used under sequential modeling to validate the methodological enhancements and to evaluate network performance. The system annual operating costs are reduced when using the proposed TVTR model.
\end{abstract}

Keywords - adequacy; thermal rating; transmission losses; deterministic and probabilistic frameworks; network security; sequential modeling

\section{INTRODUCTION}

Network operators usually implement deterministic N-1 (or $\mathrm{N}-2$ and/or N-D) outage criteria [1]. Through the implementation of any of these criteria, operators inherently rely on the pre-supposition that the network is not exposed to the risk of load curtailment following one, two or double circuit component failures. Nonetheless, this assumption is flawed, because in reality the system is always exposed to risk of failure, and subsequently to customer outages in spite of the operator's ability to minimize this risk by implementing post fault corrective actions. Therefore, probabilistic methods have been proposed to tackle these problems [2]-[5]

In principle, the reliability criterion under probabilistic evaluation is superior to the deterministic one. Therefore, there is an imperative need to adopt probabilistic metrics to optimize and enhance network operation and planning [6]. The metrics of utilising a probabilistic framework are rendered through their inherent ability to account for the vast range of uncertainties that surround the behaviour of generation and transmission units. Thus historically, by simulating the system random behaviour through techniques such as the Monte Carlo Simulation (MCS), reliability engineers have been able to accurately measure system's performance through the estimation of probabilistic indices of interest [7]. Consequently, much attention is now being placed on performing probabilistic reliability assessment by considering an advanced power system operating paradigm. This paradigm is associated with the proliferation of power systems technologies that promise to enhance its flexibility amid uncertain operating environments, for example through the influx of renewable generation. Examples of flexible concepts include: Demand Side Management [8], Special Protection System with ICTs [9], wind farms [10], FACTs [11] and Dynamic Thermal Rating (DTR) [12].

Due to the limited consideration of reliability analyses of networks with DTR in the literature, there is an increasing interest in modelling the power networks considering DTR for various components. In [12] a reliability assessment methodology that considers the modeling of DTR based on randomly generated ratings using a normal probability distribution function (PDF) has been proposed. The analysis implements the aging of the most critical lines which thus allows for OHL management decisions to be made during emergency operation. A probabilistic method using seasonal thermal ratings instead of the static thermal rating is used in [13]. The proposed seasonal thermal rating model considers a set of probabilistic ratings, which are based on the season of year, or time of day. As a result, the thermal ratings are closer to the actual ampacity of the lines and higher utilization of the network is achieved.

In this context, the aim of this paper is twofold. First, it shows that probabilistic reliability assessment remains a pioneering approach when the thermal ratings based on OHL's properties are accounted for. This can be a significant premise, since recent updates related to network operation and planning are highly controversial for transmission utilities. Second, it demonstrates the benefits of considering the actual power losses of the transmission lines and TVTR based on a sequential MCS to increase operator flexibility and reduce operational costs.

\section{NETWORK MODELLING CONSIDERING OHL PROPERTIES}

\section{A. OHL adequacy modelling}

In the current operating regime, a constant conservative thermal rating is usually considered for a transmission line assuming the worst possible weather conditions. However, in 
practice, the thermal rating of transmission lines depends on the weather conditions and therefore it changes as these conditions change with time [14]. In particular, conductor operation is affected by its operating temperature, which in turn is affected by the heat produced from the current flowing through it, its thermal properties as well as the surrounding ambient conditions in which it is operating. This temperature initially rises due to Ohmic losses $\left(\mathrm{I}^{2} \mathrm{R}\right)$ and solar heating. The increasing temperature is balanced by both convection and conductor radiation cooling mechanisms. Convection cooling is a major source of heat loss and it is mainly affected by the wind speed, whereas conductor radiation is affected by the conductor temperature and the conductor's material and size. The wind speed $\left(\mathrm{V}_{\mathrm{m}}\right)$, direction $\left(\mathrm{K}_{\text {angle }}\right)$, and ambient temperature $\left(\mathrm{T}_{\mathrm{a}}\right)$ are used for the modeling of the OHL adequacy. The hourly weather data of 5 years from 1997 to 2001 were obtained from BADC Met office MIDAS stations for Aonach UK area [15]. In order to simplify the simulations the analysis was performed only for a year using the average value of each year for the hourly measurements $\left(\mathrm{V}_{\mathrm{m}}, \mathrm{K}_{\mathrm{a}}, \mathrm{T}_{\mathrm{a}}\right)$. Therefore, a single year of average values is used for the sequential analysis. According to the deterministic approach in IEEE standards [16], the maximum current that a line can carry is derived by the steady state balance heat equation as shown in (1.1).

$$
\begin{aligned}
& I=\sqrt{\left(P_{c}\left(T_{c}, T_{a}, K_{\text {angle }}, V_{m}\right)+P_{r}\left(T_{a}, T_{c}\right)-P_{s}\right) / R\left(T_{c}\right)} \\
& \mathrm{P}_{\mathrm{c}}=\text { convection heat loss, } \mathrm{W} / \mathrm{m} \\
& \mathrm{P}_{\mathrm{r}}=\text { radiated heat loss, } \mathrm{W} / \mathrm{m} \\
& \mathrm{P}_{\mathrm{s}}=\text { solar heat gain, } \mathrm{W} / \mathrm{m} \\
& \mathrm{R}=\text { ac conductor resistance at operating temperature, } \Omega / \mathrm{m} \\
& \mathrm{I}=\text { conductor current, amperes } \\
& \mathrm{T}_{\mathrm{c}}=\text { conductor temperature, }{ }^{\circ} \mathrm{C}
\end{aligned}
$$

The effect of solar heat gain is small when compared to the other heat gain mechanism (Joule losses) and therefore, for simplicity, the solar heat gain parameter is omitted in this work [17].

The IEEE RTS network studied here is assumed to have overhead line structures with a single Drake conductor configuration for the $138 \mathrm{kV}$ part and twin Grosbeak configuration for the $230 \mathrm{kV}$ part.

\section{B. STR and SeTR modelling}

Many transmission companies usually use a fixed thermal rating for short-term and long-term planning studies, which is calculated assuming extreme weather conditions and maximum conductor temperature, which can be tolerated by the OHL system (conductor annealing and maximum sag). The fixed thermal rating is usually calculated for summer, due to higher ambient temperatures, which considerably affects the maximum capacity of the line. In this paper STR and SeTR fixed thermal rating models are implemented as shown below:

1) STR: An annual fixed thermal rating based on $40{ }^{\circ} \mathrm{C}$ ambient temperature, $0.61 \mathrm{~m} / \mathrm{sec}$ wind speed perpendicular to the conductor and $75{ }^{\circ} \mathrm{C}$ and $95{ }^{\circ} \mathrm{C}$ conductor temperature for the normal and emergency operation respectively.

2) SeTR: A seasonal fixed thermal rating implemented considering the same ambient conditions as in STR with a seasonal $\mathrm{T}_{\mathrm{a}}$ varying from summer $\left(40{ }^{\circ} \mathrm{C}\right)$, spring/fall $\left(9{ }^{\circ} \mathrm{C}\right)$, and winter $\left(2{ }^{\circ} \mathrm{C}\right)$. The sequential modelling of the seasons is set (in hours) as 1 to 1416 hours and 8017 to 8760 hours for winter, 3625 to 5832 hours for summer, and 1417 to 3624 hours and 5832 to 8016 hours for spring and fall.

Table I presents the calculated ratings of Drake and Grosbeak conductors based on the seasonal weather conditions using the methodology described in [18], [19].

TABLE I.

SEASONAL CONDUCTOR THERMAL RATINGS IN IEEE RTS NETWORK

\begin{tabular}{|l|ccc|}
\hline \hline $\begin{array}{c}\text { Conductor } \\
\text { type }\end{array}$ & Summer (STR) & Spring/Fall & Winter \\
\hline Drake & 200 & 270 & 280 \\
Grosbeak & 540 & 730 & 770 \\
\hline \hline
\end{tabular}

\section{TVTR modelling}

In order to determine the real transmission capacity that is available on a given network, the methodology used in this paper uses an iterative algorithm that considers the TVTR in an annual basis. Consequently, the annual chronological load curve can be used with the annualized TVTR values. In this study only the lines that are critically loaded are assumed to have the TVTR capability considering only steady-state conductor temperature calculations for the OHL adequacy. In order to identify the critically loaded lines two case studies are implemented: one assuming the system is intact and the other assuming unexpected events occur, e.g. line outages. It should be stressed that in the analysis all the OHLs of the IEEE network have been assumed to be exposed to the same ambient conditions $\left(\mathrm{V}_{\mathrm{m}}, \mathrm{T}_{\mathrm{a}}\right.$ and $\left.\mathrm{K}_{\text {angle }}\right)$.

When the TVTR of the conductor is considered the resistance of the conductor is affected as well as the conductor temperature based on the hourly loading of the network. Consequently, the hourly weather conditions and load parameters (i.e. the power flow of the IEEE RTS) should be indicated along with the conductor properties in order to calculate the conductor temperature at a given hour. This is implemented using an iterative calculation for Tc indicated in Fig. 1 considering an initial conductor temperature of $75^{\circ} \mathrm{C}$ and $95^{\circ} \mathrm{C}$ for the normal and emergency operation conditions.

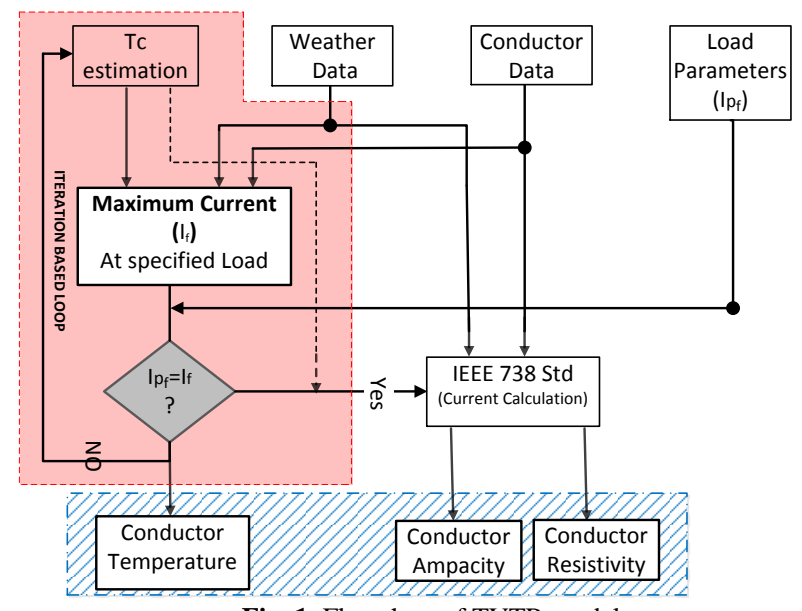

Fig. 1. Flowchart of TVTR model

Fig. 1 illustrates the flowchart of the calculations performed for the evaluation of the TVTR model which calculates the line 
temperature, the line rating, and the conductor resistance at a specified hour. In Fig. 1 the conductor data are the conductor diameter, the manufacturer resistance at $25{ }^{\circ} \mathrm{C}$ and $75{ }^{\circ} \mathrm{C}$, as well as the line reactance that is provided by the IEEE RTS. The weather data consist of wind speed, direction, and ambient temperature. Finally the load parameters constitute the calculated ampacities of the most critical lines based on the network status at any hour of study for the given load level.

The steps of the methodology are explained below:

1) Initially, the conductor data and hourly weather data are used to estimate an initial hourly varying maximum thermal rating $\left(\mathrm{I}_{\mathrm{i}}\right)$.

2) The load flow $\left(\mathrm{I}_{\mathrm{pf}}\right)$ parameters of the lines are calculated after using AC Optimal Power Flow (OPF) formulation [20] for the IEEE RTS network considering the operation conditions (i.e. failures if any) and the initial hourly varying maximum thermal rating $\left(\mathrm{I}_{i}\right)$.

3) The final hourly varying maximum thermal rating $\left(\mathrm{I}_{\mathrm{f}}\right)$ for each critical line is calculated using an iterative loop which stops when $\mathrm{I}_{\mathrm{f}}=\mathrm{I}_{\mathrm{pf}}$.

4) When $I_{f}=I_{p f}$ then the conductor hourly power flow for the specified operating conditions (i.e. network status and load profile) is used to calculate the conductor temperature following the method of IEEE standards [16]. The conductor ampacity and resistance are also calculated.

The analysis of the results in this paper is based on two TVTR models: the actual (TVTRac) and the conservative (TVTRcon).

Actual TVTRac: The calculations of this model use the iteration based method to determine the thermal capacity of the conductor and its corresponding resistance. The weather conditions are considered for the calculation of the maximum allowable temperature of the overhead conductor which is set to $75{ }^{\circ} \mathrm{C}$ for normal operation and $95^{\circ} \mathrm{C}$ for emergency operation.

Conservative TVTRcon: This model considers the conductor resistance as a constant value calculated at $75{ }^{\circ} \mathrm{C}$ or $95{ }^{\circ} \mathrm{C}$ conductor temperature for normal and emergency conditions.

\section{Losses in transmission network}

Losses in a transmission network depend on the network topology and generation pattern. In some cases the losses are considered to be at around 4\% [21]. From the transmission planning point of view, losses indeed have an impact on the generation dispatch that consequently affects the required transmission capacities. Considering that there should be a trade-off between the level of network investment in redundant components and the power losses due to potential contingencies [2], transmission planning approaches need to be revised.

Consequently the impact of weather conditions and the line loading on the OHL resistance are considered in the calculation of the transmission power losses. This is very important since the loss of one or more network components can lead to emergency operation of the network stressing the transmission lines. Therefore, both the conductor temperature and subsequently the resistance of the line will be increased affecting power losses.
Transmission losses in this paper are calculated subject to the resistance volatility of OHL's conductor, with the conductor's resistance being calculated solely as a function of conductor temperature as indicated in (1.2)

$$
R\left(T_{c}\right)=\left[\frac{R\left(T_{75}\right)-R\left(T_{25}\right)}{50}\right]\left(T_{c}-T_{25}\right)+R\left(T_{25}\right)
$$

$\mathrm{T}_{\mathrm{c}}$ is the conductor temperature

$R\left(T_{25}\right)$ is the conductor ac resistance at $T c=25^{\circ} \mathrm{C}$

$R\left(T_{75}\right)$ is the conductor ac resistance at $T c=75^{\circ} \mathrm{C}$

The losses in a transmission line are calculated by the following equation obtained from the ac non-linear formulation:

$$
\begin{aligned}
& \text { Ploss }_{L}=G_{i, j}\left(V_{i}^{2}+V_{j}^{2}-2 V_{i} V_{j} \cos \left(\theta_{i}-\theta_{j}\right)\right) \\
& \mathrm{V}_{\mathrm{i}}, \mathrm{V}_{\mathrm{j}} \text { are the voltage magnitudes, of bus } \mathrm{i} \text { and } \mathrm{j} \text {. } \\
& \theta_{\mathrm{i}}-\theta_{\mathrm{j}} \text { is the angular difference. } \\
& \mathrm{G}_{\mathrm{i}, \mathrm{j}} \text { is the real part of the (i-j) element of the nodal } \\
& \text { admittance matrix. }
\end{aligned}
$$

Since accurately determining the active power losses is of great importance when evaluating the alternative system operation strategies, this paper refers to active losses (MW), while reactive losses (MVAr) are of different nature and their consideration goes beyond the scope of this work.

\section{E. Network Operation Modules}

The deterministic approach of this paper only considers N-1 outages of the lines, therefore for all system states the Probability equals to 1 . The system is operated under the occurrence of a credible outage without causing voltage instabilities and load shedding. The Probability $\left(\mathrm{P}_{\mathrm{i}}\right)$ of each state is calculated by using (1.4), assuming that all outages are independent, and the Forced Outage Rate (FOR) [22] by using (1.5)

$$
\begin{aligned}
& P_{i}=\left\{\begin{array}{cc}
1-F O R_{i} & \text { up } \\
F O R_{i} & \text { down }
\end{array}\right. \\
& \text { FOR }=\frac{\lambda}{\lambda+\mu}
\end{aligned}
$$

$\lambda$ and $\mu$ is the failure rate and the repair rate of the units respectively.

Probabilistic reliability evaluation is implemented by using sequential MCS in order to incorporate the TVTR model. In particular, the method considers that transmission lines are represented by a two state model: up and down. Exponential distribution function is used to identify the mean values of time to failure (TTF) and time to repair (TTR) of the lines and can be expressed by the following equations.

$$
\begin{aligned}
& T T F=-\frac{1}{\lambda} \ln U_{1} \\
& T T R=-\frac{1}{\mu} \ln U_{2}
\end{aligned}
$$

$\mathrm{U}_{1}$ and $\mathrm{U}_{2}$ are random numbers in the range $(0,1)$

The index used in this paper to evaluate the reliability of implementing TVTR is the energy expected not supplied (EENS, MWh/y) and is given by (1.8). 
EENS $=\sum_{i=1}^{N L}\left(\sum_{s e F_{i}} P(s) C(s)\right) T_{i}$

$\mathrm{C}(\mathrm{s})$ is the load curtailment in state $\mathrm{s}$

$\mathrm{P}(\mathrm{s})$ is the probability of system state $\mathrm{s}$

$\mathrm{NL}$ is the number of load levels

$\mathrm{T}_{\mathrm{i}}$ is the total number of the one period cycle (hours)

$F_{i}$ is the set of all system states associated with load curtailment

The estimate of EENS, its variance, and the coefficient of variation $(\mathrm{COV})$ are defined by (1.9).

$\operatorname{COV}=\frac{\sqrt{\operatorname{Var}(E(F(x)))}}{E(F(x))}$

$\operatorname{Var}(\mathrm{E}(\mathrm{F}))$ is the variance of the estimated index

For both studies (deterministic and probabilistic) the normal operation (no outages occur) conductor temperature, $\mathrm{T}_{c}$, is set at $75^{\circ} \mathrm{C}$ based on avoidance of the conductor annealing [14], [23].

A line is defined to be at emergency state, when another transmission line connected on the same bus (as the one in emergency state) has failed. In cases a failure of a line does not result in a credible outage then lines are considered as being at normal operation state. In the present study under emergency operation the maximum conductor operating temperature is considered to be $95^{\circ} \mathrm{C}$.

\section{RESULTS}

The effect of the conductor resistance on the overall network performance is examined on the IEEE RTS79 network [24]. The studies are performed using the probabilistic and deterministic reliability analysis under STR, SeTR, and TVTR. The IEEE system contains 38 lines and 32 generators of varying types such as hydro, coal/steam, nuclear. The total peak load of the system is $2850 \mathrm{MW}$, while the total generating capacity is $3405 \mathrm{MW}$.

The algorithm was developed on Matlab using modified Matpower for the power flow calculations [25]. Matpower and more specifically MIPS are used to solve the AC OPF with minimization of the load curtailment and minimization of the generation costs objective functions.

In order to determine the importance of each transmission line and select the critical lines of the network that would benefit from real time thermal rating, an additional scenario of $1.3 \mathrm{pu}$ of normal power load is used. For this study the Sequential MCS is used assuming up to $5^{\text {th }}$ outage level for transmission lines as well as coefficient of variation $(\mathrm{COV})$ to be lower than $5 \%$, as stopping criterion [7]. The number of occasions when more than $80 \%$ loading occurred for a transmission line is recorded. This loading study is performed for both intact and contingent networks and for both static thermal rating and seasonal thermal rating models. The results from the study indicated that L11 is the most frequently overloaded line for the $138 \mathrm{KV}$ part of the network

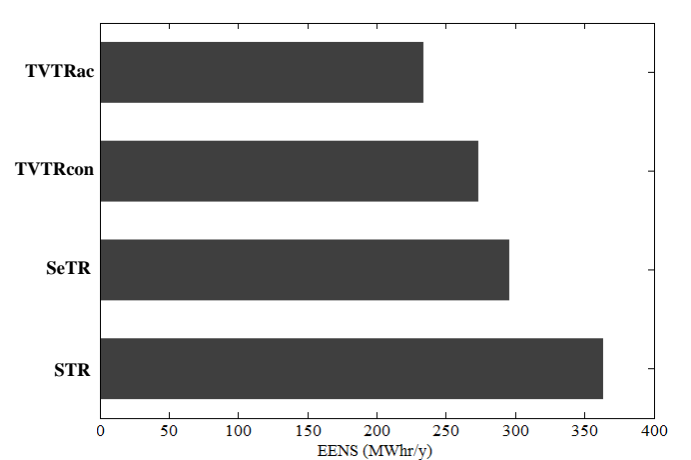

Fig. 2. EENS index according to three thermal operation models

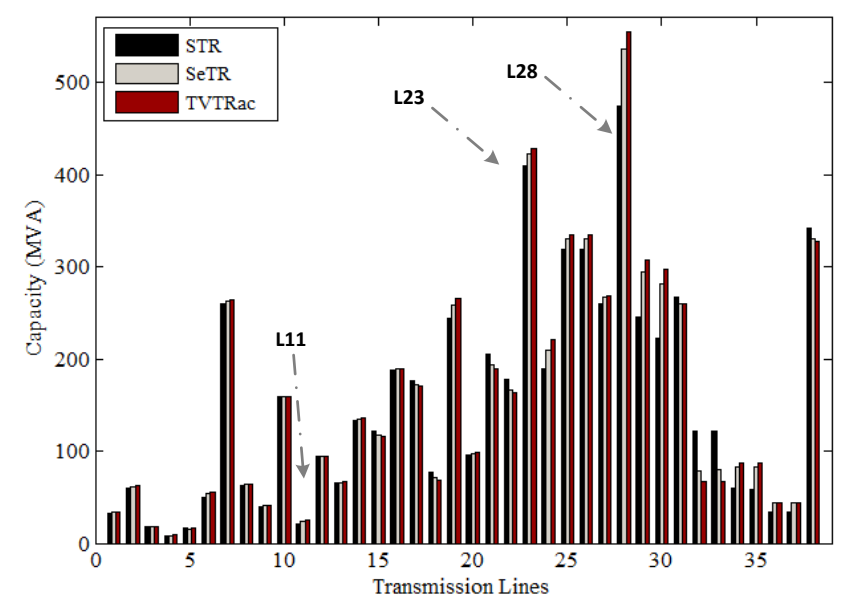

Fig. 3. Power Capacity of lines under probabilistic analysis

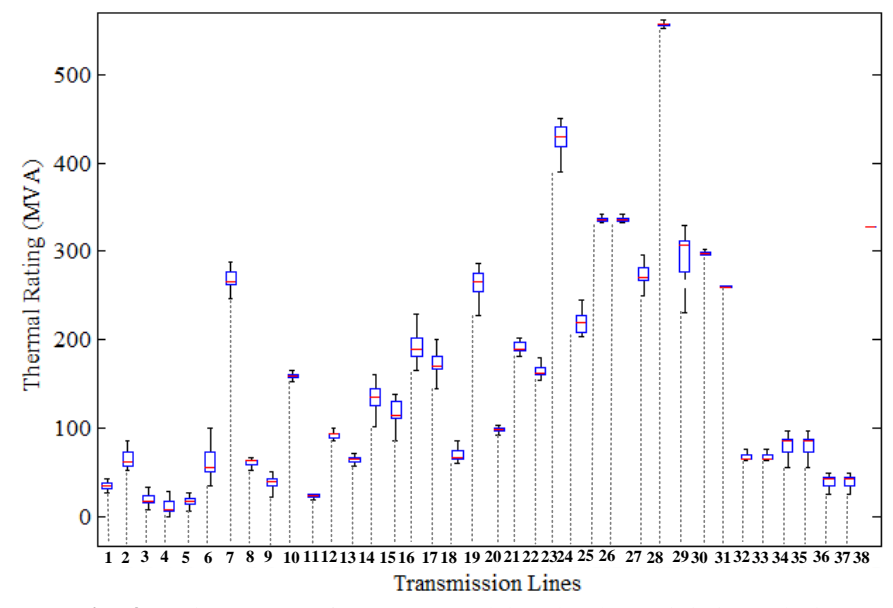

Fig. 4. Rating (MVA) for TVTR model under deterministic analysis

and L23, L28 for the 230KV part. Although L11 shows the highest overloaded probability compared to the other OHLs of the same voltage level, the value of its probability is very small and this can be clearly seen within its low average capacity (Fig. 3).

When the different thermal rating models are considered for the reliability performance of the network then the most secure and economic scenario is the $\mathrm{TVTR}_{\mathrm{ac}}$. This can be observed in Fig. 2 where the EENS reliability index for the three thermal rating scenarios is shown. The $\mathrm{TVTR}_{\mathrm{ac}}$ model resulted in $24.79 \%$ lower EENS than the STR model. This is mainly due to the increased capacity of transmission lines provided from the TVTR model and the smarter AC OPF that is implemented due to change on resistance that is considered in the model. 


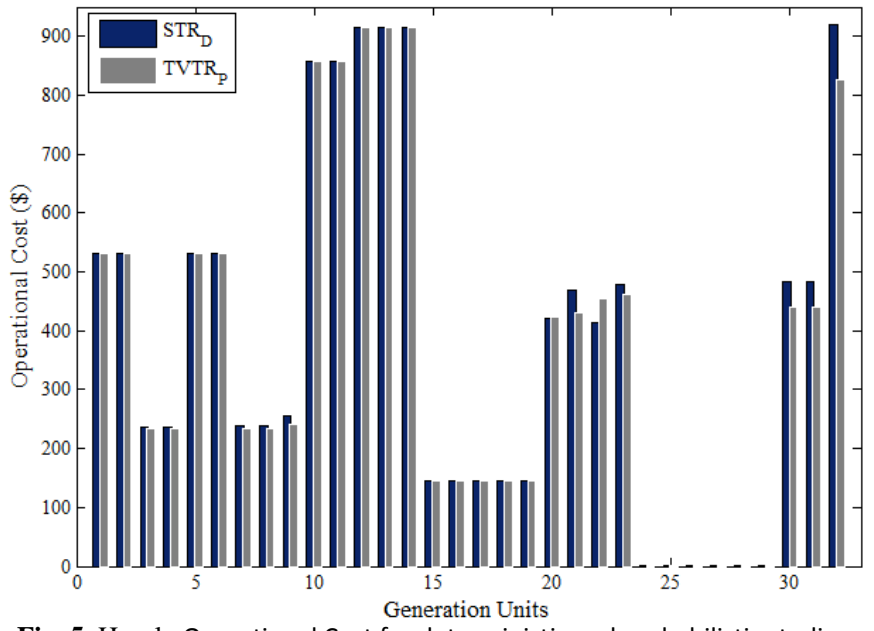

Fig. 5. Hourly Operational Cost for deterministic and probabilistic studies

From Fig. 2 it can also be derived that the SeTR improves the network performance by $17 \%$ and the TVTR $_{\mathrm{ac}}$ provides an additional $21 \%$ improvement. However even when the more conservative scenario $\left(\mathrm{TVTR}_{\text {con }}\right)$ is used the increase in network performance is a substantial $14.68 \%$ indicating that the resistance of the network affects considerably the network EENS.

To quantify the impact of different thermal rating approaches on conductor thermal stress, the average capacity of the lines is illustrated in Fig. 3. It can be inferred that the ratings of L11, L23 and L28 are higher in TVTR strategy with the capacity of L23 showing the most notable increase, from 474 MVA (STR) to almost 560 MVA. It can also be observed that other lines (e.g. L3, L18, L22, L31, L32, L33 and L38) demonstrate equal or lower loadings when the TVTR strategy is utilised. The reason for this is that the increase in the power flows of other lines (due to increased ampacity from the TVTR) resulted in reduction of the power flow through those lines. Fig. 4 depicts the average values of the thermal ratings for $\mathrm{TVTR}_{\mathrm{ac}}$ under deterministic analysis. It displays several features about the transfer capacity of transmission lines, such as the median of Rating value, the upper quartile (representing the amount of populations which are higher than the median population- $25^{\text {th }}$ percentile), the lower quartile (representing the amount of populations which are lower than the mean population- $75^{\text {th }}$ percentile) and the line or whisker which extends from each box (representing the largest or the smallest point within 1.5 interquartile range from the previous quartile). These characteristics can provide system operators with vital inputs suggesting TVTR network reinforcement under conservative-deterministic operation regime. The most critical lines are utilized less compared to the probabilistic case, by a factor of $3.6 \%$, which occurs due to the power margins set to the network by the deterministic approach. The upper and lower quartiles of OHL 6,23,24,27,28 show high variance, which indicates that they are occasionally overloaded and hence system operators' should take actions to further utilize them. In sum, the results of thermal rating analysis show that ultimate capacities driven by the TVTR model are associated with higher levels of utilization.

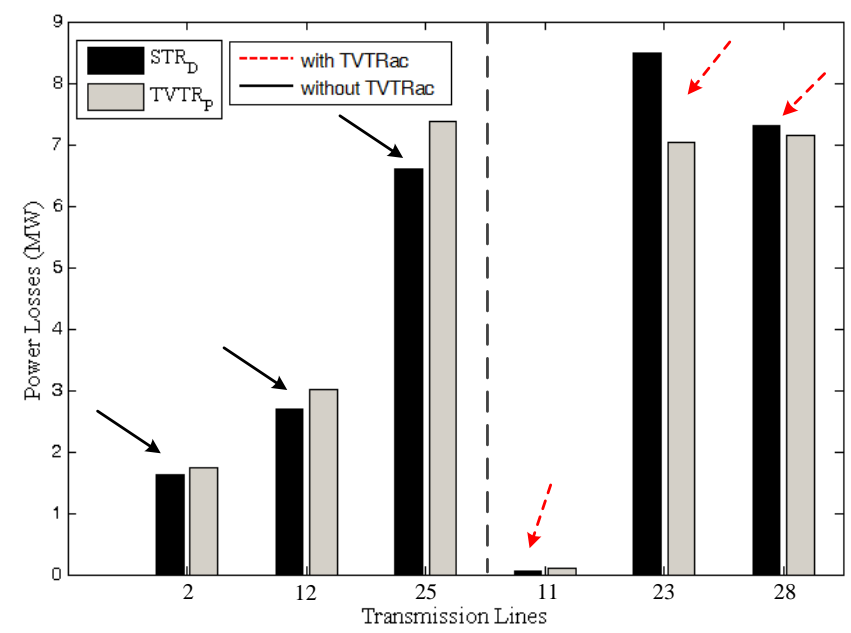

Fig. 6. Transmission Power Losses under TVTR operations

Fig. 5 compares the operational costs of STR under deterministic operation and the proposed TVTR under probabilistic criteria. The operational costs of transmission reinforcement are higher in the deterministic approach. In particular, operational costs of generation units 8-9, 21-23, 3032 have been considerably reduced due to TVTR $_{\mathrm{ac}}$ model, while a slight difference is seen in operational costs of 1-7 and 10-20 generators. Consequently, the deterministic dispatch under STR model is inefficient with respect to hourly total costs and increased by a factor of $2.1 \%$. This is mainly because TVTR under the probabilistic analysis allows the cheapest generators to generate more energy considering the most updated thermal loading of the OHL.

Figure 6 illustrates the average value of active power losses assuming STR and TVTR (for both operating modules). For simplicity, the average active losses of six lines of the network are shown. The three lines (on the right of the figure) constitute the most critical lines when TVTR model has been applied; whereas the other three (on the left of the figure) are the most critical loaded when the analysis is performed with the fixed rating model.

It is obvious that the losses of the critical lines are reduced in probabilistic case study since the real conductor temperature is proportional to the conductor resistances. On the other hand, L2, L12 and L25 are modelled with their resistance values being constant to the maximum operating conditions independently of the actual loading of the line. Therefore, the increase in losses is the result of the increased current flows of the lines from the TVTR ratings.

Consequently, using time dependent ratings affect the power flows within the network and thereby the losses of the lines. This indicates that network losses are affected by the thermal rating model used for the analysis and by the network outage conditions (severe or not).

Table II presents the total active power losses of IEEE RTS network under the various operation regimes. According to [21] the total system losses of IEEE RTS system considering 1p.u. load is $51.6984 \mathrm{MW}$. It can be seen from Table II that increased losses have been computed on this work accounting for higher thermal ratings of the lines due to consideration of their contingency state and its duration as well as the load level (1.3pu) of the network. In particular, power losses under probabilistic $T V T R_{a c}$ are $2.15 \%$ lower than deterministic STR. 
This shows the necessity of transmission utilities to operate the network considering the actual power losses with the view to make decisions for optimum generation placement and dispatch.

TABLE II

TOTAL POWER TRANSMISSION LOSSES (MW) ACCORDING TO NETWORK OPERATION MODULES FOR THE IEEE 24 BUS SYSTEM

\begin{tabular}{|l|cccc|}
\hline \hline \multicolumn{1}{|c|}{ NETWORK } & \multicolumn{4}{|c|}{ Ratings (MVA) } \\
MODE & $S T R$ & $T V T R_{a c}$ & $S e T R$ & $T V T R_{c o n}$ \\
\hline Intact & 83.18 & 86.07 & 89.59 & 86.13 \\
Deterministic & 88.60 & 91.40 & 96.30 & 96.18 \\
Probabilistic & 83.79 & 86.69 & 90.35 & 86.75 \\
\hline \hline
\end{tabular}

\section{CONCLUSION \& FURTHER WORK}

This paper presents analysis of STR, SeTR and TVTR strategies for determining transmission conductor thermal ratings and their corresponding active losses in both probabilistic and deterministic analysis. By evaluating the real transfer capability and transmission losses, further security margins can be set and thereby assist the system operators to cost effectively resolve the post fault contigencies within TVTR as well as to make better decisions for alternative power system expansion plans by accounting for real active losses realisation.

It is highlighted that the annual operational cost of the network is reduced by $35 \%$ when TVTR and the probabilistic approach is considered against the conventional deterministic and STR approach.

Furthermore, the modelling allows for more precise calculation of the losses of the network. This indicated the decrease of losses during the TVTR and the probabilistic approach against the conventional deterministic and STR approach as a result of better utilisation of network actual adequancy and increased loading of specific lines that provide connection to cheaper generators.

The presented operation model can be further enhanced including multiple operating states (normal,alert,contigency and ancillary contigency) derived from the outages level and quantify the risk tolerance of using probabilistic framework.

\section{REFERENCES}

[1] L. Söder, J. Douglas, and A. Ekwue, "Study on the Technical Security Rules of the European Electricity Network," Stockholm, 2006.

[2] W. Li and P. Choudhury, "Probabilistic Transmission Planning," IEEE Power Energy Mag., vol. 5, pp. 46 - 53, 2007.

[3] J. D. McCalley et al., "Probabilistic security assessment for power system operations," in Power Engineering Society General Meeting, 2004, pp. $212-220$.

[4] J. M. Arroyo and N. Alguacil, "A Risk-Based Approach for Transmission Network," IEEE Trans. Power Syst., vol. 25, no. 3, pp. 1759-1766, 1995.

[5] D. S. Kirschen, K. R. W. Bell, D. P. Nedic, D. Jayaweera, and R. N. Allan, "Computing the value of security," in IEE ProceedingsGeneration, Transmission and Distribution, 2003, vol. 150, pp. 673 -678 .

[6] R. Moreno, D. Pudjianto, and G. Strbac, "Transmission Network Investment with Probabilistic Security and Corrective Control," IEEE Trans. POWER Syst., vol. 28, no. 4, pp. 3935-3944, 2013.

[7] R. Billinton and W. Li, Reliability Assessment of Electrical Power Systems Using Monte Carlo Methods. New York: London:Plenum, 1994, pp. 35-36.
[8] I.-S. Ilie, I. Hernando-Gil, A. J. Collin, J. L. Acosta, and S. Z. Djokic, "Reliability Performance Assessment in Smart Grids with Demand-side Management," in ISGT Europe, 2011, pp. 1-7.

[9] B. Falahati, Y. Fu, and L. Wu, "Reliability Assessment of Smart Grid Considering Direct Cyber-Power Interdependencies," IEEE Trans. POWER Syst., vol. 3, no. 3, pp. 1515-1524, 2012.

[10] R. Billinton and W. Wangdee, "Reliability-Based Transmission Reinforcement Planning Associated With Large-Scale Wind Farms," IEEE Trans. Power Syst., vol. 22, no. 1, pp. 34-41, Feb. 2007.

[11] R. Billinton, M. Fotuhi-Firuzabad, S. O. Faried, and S. Aboreshaid, "Impact of Unified Power Flow Controllers on Power System Reliability," IEEE Trans. POWER Syst., no. I, 2000.

[12] C. Tumelo-Chakonta and K. Kopsidas, "Assessing the Value of Employing Dynamic Thermal Rating on System-wide Performance," in ISGT Europe, 2011, pp. 1-8.

[13] J. Heckenbergerova, P. Musilek, and K. Filimonenkov, “Assessment of Seasonal Static Thermal Ratings of Overhead Transmission Conductors," IEEE Power Energy Soc. Gen. Meet., pp. 1-8, 2011.

[14] K. Kopsidas, S. M. Rowland, S. Member, and B. Boumecid, "A Holistic Method for Conductor Ampacity and Sag Computation on an OHL Structure," IEEE Trans. Power Deliv., vol. 27, no. 3, pp. 1047-1054, 2012.

[15] "http://badc.nerc.ac.uk/data/ukmo-midas/WPS.html."

[16] "IEEE Standard for Calculating the Current-Temperature of Bare Overhead Conductors," IEEE Std 738-2006 (Revision Std 7381993), pp. c1-59, 2007.

[17] C. T. B. TB 299, "Guide for the Selection of Weather parameters for Bare Overhead Conductor Ratings," 2006.

[18] K. Kopsidas and S. M. Rowland, "A Performance Analysis of Reconductoring an Overhead Line Structure,” IEEE Trans. Power Deliv., vol. 24, no. 4, pp. 2248-2256, Oct. 2009.

[19] K. Kopsidas, "Assessing the power transfer performance of a lattice tower overhead line system," IET Gener. Transm. Distrib., vol. 7, no. 1, pp. 90-100, Jan. 2013.

[20] X. Wang and Y. Song, Modern Power Systems Analysis. New York: Springer, 2008.

[21] A. M. Leite and J. Guilherme, "Transmission Loss Allocation : Part I - Single Energy Market," IEEE Trans. Power Syst., vol. 18, no. 4, pp. 1389-1394, 2003

[22] R. Billinton and R. N. Allan, Reliability Evaluation of Power Systems. New York: Plenum, 1984, pp. 21-29.

[23] "IEEE Guide for Determining the Effects of High-Temperature Operation on Conductors, Connectors, and Accessories," IEEE Std 1283-2004, pp. 1-28, 2005.

[24] P. M. Subcommittee, "IEEE Reliability Test System," IEEE Trans. Power Appar. Syst., no. 6, pp. 2047-2054, 1979

[25] R. D. Zimmerman, E. M.-S. Carlos, and D. Gan, "MATPOWER:A MATLAB Power System Simulation Package, Version 3.1b2, User's Manual." Power Systems Engineering Research center(PSERC), Tech. Rep. 2006, New York, 2011. 